\title{
A Research on E Learning Model Using Adaptive Classification Method
}

\author{
Pujari Vinayak, R.B. Patil
}

\begin{abstract}
:- due to the improvement of records and correspondence upgrades in changed fields, which have moreover stimulated the educational exercise section, accommodative e-gaining knowledge of frameworks are perceived generally of the preeminent eye catching exam areas in separation on-line education. This studies route permits engineers to accumulate a model of goals, inclinations and information of every man or woman client an amazing manner to alter the instructive to his/her desires and traits. The intention of this paper is to blessing the excellent in elegance in accommodative e-mastering frameworks as every different to the normal gaining knowledge of by way of portraying its measurements, plan, layout and hypothetical techniques. We generally tend to moreover feature some opportunities for our destiny work via discovering, dissecting and scrutinizing present frameworks..
\end{abstract}

Catchphrases Adaptive getting to know, e-learning, putting parameters, scholar attributes, savvy mentoring frameworks, flexible hypermedia frameworks.

\section{INTRODUCTION}

E-gaining knowledge of is one some of the examination areas which have pulled in the attention of the severa professionals inside the course of new a long time. no matter its intricacy, numerous works have raised eye catching troubles, specifically the trouble of mastering assets openness to assure "learning for all". according with [1], mastering assignment isn't totally to make assets open to all people, anyplace, whenever and in some configurations, yet in addition to deliver the training in the spot, time and exact sufficient way. subsequently, seems into have given greater significance to split schooling, and pretty to e-adapting as a way to enhance university college students' exhibition and arrive at their success [2].

in this aspect of view, the contextualization of reading can be another worldview for bendy frameworks as a way to treatment the commonplace learning limits [3] that isn't always any extra extended equipped to provide intuitiveness, timespan execution, discretion, personalization of scholarly content, versatile agency of advent and getting to know path. flexible frameworks assume to alter the mastering's antiquated methodology on the manner to satisfy the students' desires [4].

The primary purpose of this paper is to ponder the idea of versatile getting to know, to suggest its measurements and to

Revised Version Manuscript Received on 16 September, 2019.

Pujari Vinayak, Research Scholar, Department of Computer science and engineering, Research Scholar, Shri JJTU, Rajasthan, India.

(Email: vinayakpujari86@gmail.com)

Dr. R.B. Patil, Professor, Department of Computer science and engineering, S.K.Somaiya College of Arts, Science and Commerce, Mumbai, Maharashtra, India.

(Email:patilrajendrab@gmail.com) take a look at the frameworks created in view that 2010. to perform this target, we want to pose the accompanying inquiries: What is a versatile understanding framework? what is the format on which any flexible e-mastering framework is primarily based absolutely? What are the methodologies that we will use to execute those fashions and designs? ultimately, what are the run of the mill answers for each method?

In mild of these inquiries, this text is prepared as pursues: The number one section attracts at the concept and the that means of flexible e-learning frameworks. the subsequent segment presentations the engineering and the primary segments of these to demonstrate the flexible gaining knowledge of in reality because the everyday frameworks of each technique. The remaining issue manages the associated features just as effective remarks about our future enhancements

\section{ADAPTIVE LEARNING SYSTEMS}

\section{Digital Getting To Know (E-Studying)}

most of appears into signify learning with the aid of the growth of studying in a quantitative way, preserving statistics, gaining aptitudes and strategies that may be applied while essential, translating and information reality in an change way [5][6]. In 1984, the writer in [7] characterised mastering as a method wherein records is made thru the change of involvement. This approach is characterised as a 4-put together cycle that speaks to the approach for seeing, questioning, feeling, and appearing which indicates up when we are going through new encounters. The 4 stages contain being associated with every different revel in, growing perceptions, making hypotheses to make clean the perceptions, to attend to troubles and take picks. As indicated through [8], e-mastering is some other approach to train and study. In [9], the creator expresses that e-studying relies upon on 3 crucial criteria. within the first location, e-mastering is ready and that lets in to ongoing overhauling, placing away and convalescing, appropriating and sharing records. 2nd, it is conveyed to the purchaser with the resource of his/her machine making use of internet innovation. $1 / 3$, it centers round the biggest attitude on discovering that surpasses the standard ideal fashions of schooling

\section{Flexible E-Studying Framework}

studies in accommodating frameworks is regularly duplicated decrease lower back to the mid Nineteen Nineties. with the aid of then, the two noteworthy regions of 
gadget-lucid content and purchaser displaying made investigation mind as aftereffects of the level of development they got here to.

An oversized collection of studies gatherings perceived static gadget-intelligible content material problems in numerous software program regions and had started out to survey various techniques to adjust the behavior of device-lucid content frameworks to clients in accomplice in Nursing singular manner [10]. As of now, have a look at within the field of e-mastering is located inside the route of analyzing degrees any place scholar's desires, thought, getting to know plans, propensities and wishes are grade by grade taken into idea [11]. these elements feature the idea of accommodating getting to know frameworks [12] as partner in Nursing alternative in assessment to the same old approach «one-size-fits-all» inside the development of teaching materials. The creators in [13] diagram adjustment thinking about the truth that the ability of a framework to change its conduct with regards to the scholar's needs and non-compulsory features

The essential segments of every bendy framework are depicted as pursues:

\section{Wellspring Of Versatile Studying}

As consistent with [14], the wellspring of adjustment (pupil, situation or system) is diagnosed with the places of each framework just as the ideal outcome. at the off risk that the aim is the pupil, we supply extra significance to his traits. Pertinent ones are epitomized in the pupil version it is a crucial aspect for each e-gaining knowledge of framework to be bendy [15]. scholar's attributes were the issue of different inquires about in flexible e-getting to know frameworks and schooling zones. the choice of attributes relies upon the framework. As indicated thru [14], due to a static framework, the difficulty of adjustment is a popular one using the functions predefined with the resource of the scholar inside the route of his/her first usage of the framework, together with character statistics, gaining knowledge of style, dreams and inclinations. it's made before the studying manner begins. $\mathrm{Be}$ that as it is able to, dynamic adjustment requires a technique of cooperation between the consumer and the framework. All topics taken into consideration, the usage of dynamic trends refreshed constantly is required. version: abilities, feelings, level of facts, history, course and take a look at outcomes [16] [17]. the author in [18] states that the difference between those attributes shows up within the period. Static attributes are applied on a long haul premise because they communicate to wellknown statistics, at the same time as dynamic traits are carried out on a brief premise considering the truth that they are variable, specific and sensible. In some examination works, and for more proficiency and trustworthiness, scholar attributes are joined with setting parameters. as an instance: location, brilliant clamor, availability, tool implemented and client's tendencies [17].

\section{Consciousness Of Flexible Analyzing}

The creators in [17], [19] and [20] explicit that the preeminent large implemented adjustment aim is that the mastering cloth itself (mastering content material fabric). all through this situation, courses place unit supplied in a completely absolutely severa intends to every scholar. The degree of problem of schooling helps is furthermore taken into concept concurring, as an example, to the pupil's records degree. numerous investigations have declared that related backings are often custom-made to each student via adjusting endorsed connects likewise as in addition educational materials at the same time as abuse the framework [17] [21] [22]. In unique works, the steerage organization (content material creation) is often a custom prepared ebook or a combined media framework content material fabric (image, video, sound, liveliness). The software may even be custom designed to the student dispositions [17] [23] [24] [25]. moreover, the education direction are regularly customized via spotting among international course (redirection to out of doors resources) and neighborhood route (utilizing steady framework) [14] [25]. The art work displayed in [17] indicates that beneficial studying may even be a form of adjustment with the aid of the usage of making organizations of university students with number one attributes so that it will dole out every new student to the correct bunch.

\section{ADAPTIVE E-LEARNING MODELS}

\section{Complete Scale Adaptive Technique}

As indicated with the resource of [32], this method accept that the method for adjustment exists to permit university college students to transport from a route to any other with $\mathrm{A}$ customized rate. that is frequently due to college students take hassle from each different of their getting to know limits. special attributes are taken into idea, for instance, desires, tendencies, stage of data, scholarly capacities, getting to know plans, mental factor systems, scholastic inspirations, personality, encounters and accomplishments [33] [34]. The favored version of this system is predicated on a normal succession began with the resource of the instructor. as an instance, clarifying or displaying unique facts, giving models, posing inquiries, as a result giving grievance to college college students' questions. This intermittent grouping in the displaying approach thru discussing and showing the path in an academic strategies and abuse static techniques, is that the disservice of this system [35].

\section{Bent Remedy Interplay (Ati) Method}

This technique is based at the speculation referenced in [36]. The aim of the ATI technique is to find the maximum students' aptitudes via dissecting and getting his/her behavior. It also recommends converting medications to expand the framework's collaboration with college students gadgets, to encourage their life in reading matters and to broaden their achievement. As indicated thru [31], one inside the entirety approximately preeminent critical additives of the ATI technique is that the customer's management over the steerage technique. the writer has referenced that numerous investigations have moreover proposed that the discretion's prosperity is based upon the scholar capacities. it is better to restrain the administration (aggregate or incomplete) for understudies with low-in advance facts as well as to reinforce gaining knowledge of for understudies United nations

Published By:

Blue Eyes Intelligence Engineering 
organization have elite. during this particular scenario, the paintings gave in [37] characterizes three degrees of manage: universal autonomy, incomplete management among a given undertaking situation and stuck errands with the management of pace. sensible Tutoring structures (ITS) ar upheld the ATI technique over the location of clients' aptitudes. The execution of ITSs is based on the plan of flexible e-getting to know frameworks, that includes the pupil version and furthermore the place model. moreover, ITSs make use of the difference version to create and to blessing custom-made substances to each scholar [38]. versatile clever sight and sound framework frameworks are A case of this gadget. The goal is to fashion getting to know arrangements that comprise sensible sight and sound framework content material in ITSs to modify it to every scholar's profile [31].

\section{Miniaturized scale Adaptive method}

This method presents to investigate the exact college students' needs as a way to supply them with the preeminent relevant mastering method [34]. Dislike the huge scale versatile method, this gadget is dynamic due to using quantitative, brief and timespan scholar's attributes. that is often possible via dissecting and notion the student's responses and behavior over the framework in an effort to modify the training style of the reading approach [33]. This method contains numerous features over the entire scale versatile approach, which includes concept, student mistakes, passionate standing and others [35]. As in keeping with [34], this machine is predicated on two number one techniques:

\section{A. Indicative system:}

Its recognizes the students developments (aptitudes, capacities, notion, information, inclinations, gaining knowledge of vogue.

improvement method:

Its streamlines the scholar's association with the framework even though adjusting the training substance and association.

In [35], the creator specifies that ITS and flexible hypermedia frameworks are pertinent examples of this system. They employ the small scale flexible technique inside the indicative approach an excellent way to extricate the student's attributes. This method starts with the get-collectively of putting information, dissects and contrasts them and the predefined ones to relegate every new customer to the really worth magnificence. At remaining, it creates the adjustment method by using the use of adjusting substance, configuration or course.

\section{IV.END\& RESULTS}

on this paper, we've got got exhibited the device of bendy e-getting to know frameworks upheld the possibility of contextualization. we have featured the maximum additives of accommodative e-learning frameworks delineated within the stockpile, intention and adjustment manner. we have moreover referenced the plan of those frameworks made from three number one models (student, area, adjustment). Adjustment methodologies were additionally displayed by manner of particularization the extraordinary hypotheses and gift usage. At lengthy last, we have got referenced a blueprint of the commitments made at some point of this studies area during the 2010-2017 sum. we can motive that the occasion of records and correspondence advancements, and explicitly net and internet advances goodly affect the educational exercise division, making accommodative e-studying viable and important. anyways, the considerable scope of sensible assets makes students lost. inside most of cases, they grow to be demotivated due to the fact their underlying usage of the framework. also, student's territory unit extra frequently than now not in brilliant that backs their getting to know technique off after they make use of accomplice e-analyzing framework? on this unique situation, the creators in [14] particular that the check of accommodative e-getting to know engineers is to are searching for out the scholar attributes that territory unit pivotal for a skilled studying and to illustrate the effect of those characteristics at the method and the mastering execution. At present, there territory unit numerous tactics and strategies to show the student. The preference of tactics is primarily based upon the affiliation's goal and moreover the proper very last effects too for the motive that the viability of the method.

\section{REFERENCESS}

1 G. Fischer, "consumer Modeling in Human-computer interplay," consumer model. purchaser Adapt. Interface., vol. 11, no. 1-2, pp. Sixty five-86, Mar. 2001.

2 k. Colchester, H. Hagras, D. Alghazzawi, and G. Aldabbagh, "A Survey of synthetic Intelligence techniques hired for Adaptive academic structures inside E-getting to know structures," J. Artif. Intell. delicate Comput. Res., vol. 7, no. 1, pp. 47-sixty four, 2016.

3 M. Alshammari, R. Anane, and R. J. Hendley, "Adaptivity in ELearning systems," in 2014 eighth worldwide conference on complicated, smart and software program intensive structures, 2014, pp. 79-86.

4 F. Essalmi, L. J. B. Ayed, M. Jemni, Kinshuk, and S. Graf, "A sincerely personalization system of E-studying conditions," Comput. Murmur. Behav., vol. 26, no. 4, pp. 581-591, Jul. 2010.

5 P. Ramsden, gaining knowledge of to steer in higher education. Routledge, ITPBK Distribution middle, 7625 Empire Dr., Florence, KY 41042; Tel: 800-634-7064 (Toll free); web internet site: http://www.Routledge.Com (published version: ISBN-zero-415-15999-6; gentle cowl: ISBN-0-415-15200-3)., 1992.

6 M. . Smith, "gaining knowledge of speculation," infed.Org, 1999.

7 D. A. Kolb, Experiential getting to know: revel in because the source of studying and improvement. feet Press, 1984

8 T. Govindasamy, "powerful usage of e-studying: Pedagogical contemplations," net excessive. Educ., vol. 4, no. three-4, pp. 287-299, 2001.

9 M. J. Rosenberg, E-learning: strategies for handing over information in the digital Age. McGraw-Hill professional, 2002.

10 H.- D. Böcker, H. Hohl, and T. Schwab, "Upsilon-pi-ADAPT-epsilonrho: Individualizing Hypertext," in complaints of the IFIP TC13 third Interational conference on Human-laptop interaction, Amsterdam, The Netherlands, The Netherlands, 1990, pp. 931-936. 
11 S. Kulaglić, S. Mujačić, I. okay. Serdarević, and S. Kasapović, "effect of mastering styles on improving skillability of flexible instructive hypermedia frameworks," in 2013 12th global conference on information generation primarily based higher education and training (ITHET), 2013, pp. 1-7.

12 P. Brusilovsky, "versatile and sensible technology for Webbased education," 1999. [Online]. reachable: http://www.Pitt.Edu/ peterb/papers/KI-assessment.Html.

13 D. Jonassen, M. J. Spector, M. Driscoll, M. D. Merrill, and J. Van Merrienboer, handbook of studies on academic Communications and technology: A assignment of the association for instructional Communications and technology. Routledge, 2008.

14 M. Vandewaetere, P. Desmet, and G. Clarebout, "The dedication of scholar traits inside the development of computer primarily based bendy mastering conditions," Comput. Murmur. Behav., vol. 27, no. 1, pp.118-a hundred thirty, Jan. 2011.

15 P. Brusilovsky and E. Millán, "purchaser models for Adaptive Hypermedia and Adaptive educational systems," within the Adaptive net, Springer, Berlin, Heidelberg, 2007, pp. three-53.

16 okay. Verbert et al., "setting aware Recommender structures for studying: A Survey and destiny challenges," IEEE Trans. analyze. Technol., vol. five, no. 4, pp. 318-335, Oct. 2012.

17 A. Al-Hmouz, J. Shen, J. Yan, and R. Al-Hmouz, "Upgraded scholar model for versatile portable gaining knowledge of," in complaints of the 12th international meeting on facts coordination and electronic applications and administrations, 2010, pp. 783-786.

18 E. wealthy, "consumer Modeling by means of the use of Stereotypes*," Cogn. Sci., vol. 3, no. four, pp. 329-354, Oct. 1979.

19 H. Ketamo, "An Adaptive Geometry recreation for handheld devices," J. Educ. Technol. Soc., vol. 6, no. 1, pp. eighty three-ninety 5, 2003.

20 E. Reategui, E. Boff, and J. A. Campbell, "Personalization in an intuitive learning state of affairs via a virtual character," Comput. Educ., vol. fifty one, no. 2, pp. 530-544, Sep. 2008.

21 C. Conati, A. Gertner, and ok. VanLehn, "utilizing Bayesian Networks to control Uncertainty in student Modeling," user version. consumer Adapt. associate., vol. 12, no. 4, pp. 371-417, Nov. 2002.

22 A. Mitrovic, B. Martin, and M. Mayo, "utilising evaluation to shape ITS layout: consequences and experiences with sq.-instruct," person model. client Adapt. partner., vol. 12, no. 2-3, pp. 243-279, Jun. 2002.

23 Z. Jeremić, J. Jovanović, and D. Gašević, "Assessing an intelligent Tutoring machine for layout styles: the DEPTHS experience," J. Educ. Technol. Soc., vol. 12, no. 2, pp. 111-130, 2009.

24 C. Romero, S. Ventura, E. L. Gibaja, C. Hervás, and F. Romero, "digital bendy preparing take a look at gadget framework for coronary heart existence assist," Artif. Intell. Drug., vol. 38, no. 1, pp. sixty seven-seventy eight, Sep. 2006.

25 P. Brusilovsky, "versatile Hypermedia," person version. consumer Adapt. Interface., vol. 11, no. 1, pp. 87-110, Mar. 2001.

26 R. Kass, "building a purchaser version verifiably from an agreeable warning discourse," person version. customer Adapt. talk., vol. 1, no. 3, pp. 203-258, Sep. 1991.

27 J. A. Self, "Understudy models in pc supported guidance," Int. J. guy-Mach. Stud., vol. 6, no. 2, pp. 261-276, Mar. 1974.

28 E. Popescu, "Adjustment Provisioning with recognize to studying styles in a web-based totally instructional gadget: An Experimental examine," J. Comput. help. examine., vol. 26, no. four, pp. 243-257, Aug. 2010.

29 M. G. Moore, "Article: three types of cooperation," Am. J. Separation Educ., vol. three, no. 2, pp. 1-7, Jan. 1989.

30 M. A. Tadlaoui, S. Aammou, M. Khaldi, and R. N. Carvalho, "pupil Modeling in Adaptive instructional structures: A Comparative look at," Int. J. Mod. Educ. Comput. Sci., vol. 8, no. 3, p. 1, Mar. 2016.

31 B. Beldagli and T. Adiguzel, "Representing an splendid flexible e-studying: A theoretical gadget," Procedia - Soc. Behav. Sci., vol. 2, no. 2, pp. 5755-5761, 2010.

32 F. S. Keller, "'goodbye, trainer ... '1," J. Appl. Behav. Butt-centric., vol. 1, no. 1, pp. seventy nine-89, Mar. 1968. guidance and education (Bradford) forty 3 (four-five):256-267.

33 Tsai, M.- J. (2009). The version of Strategic e-studying: expertise and evaluating student e-mastering from Metacognitive views. Instructive generation and Society12 (1), 34-forty eight.

34 Venkatesh, V. furthermore, Davis, F.D. "A Theoretical Extension of the generation popularity version: 4

35 Longitudinal subject research," management technological know-how, 46, 2000, 186-204. [

36 Fayed G.S.D., H., Jihad., M., Alja'am, Samir, A.S., and Hosam, E. (2006). E-mastering model relying on semantic internet innovation. international diary of figuring and records sciences, four(2), sixty three - seventy one

37 existence structures of an eLearning Lesson: 9 events of education, blog by means of Shelley A. Gabl

38 Gagne R, Briggs L, guess W, editors. third release. the big apple: Holt, Rinehart and Winston; 1998. requirements of instructional shape.

39 step by step instructions to make use of Gagne's model of instructional structure in displaying psychomotor competencies,Kayvan Khadjooi, 1Kamran Rostami,2 and Sauid Ishaq2 Gastroenterol Hepatol mattress Bench. 2011 summer season; four(three): 116-119.

40 navy, D. R. (2011). E-mastering within the 21st century: A machine for research and exercise (second edition).London: Routledge/Falmer.

41 Morrison, Gary R. Structuring effective education, 6th edition. John Wiley and Sons, 2010.

42 Wilson, B.G., Jonassen, D.H., and Cole, P. (1993). Subjective aproaches to academic structure. The ASTD hanbook of educational innovation, 21.1-21.22). ny: McGraw-Hill. April 22, 2005.

43 The ADDIE model: academic design posted in Frameworks and Theories on January 29, 2014 with the aid of Ed wooded area.

44 Tripp,Steven, Bichelmeyer,Barbara, speedy prototyping: An choice educational shape system, educational technology research and development, 38, 1 , three/18/1990, Pages 31-forty four. 